\title{
Percepções de estudantes universitários sobre a relação professor-aluno
}

\author{
Clarissa Tochetto de Oliveira \\ Universidade Federal de Santa Maria - RS \\ Jamille Mateus Wiles \\ Universidade Federal do Rio Grande do Sul - RS \\ Pascale Chechi Fiorin \\ Universidade Federal de Santa Maria - RS \\ Ana Cristina Garcia Dias \\ Universidade Federal de Santa Maria - RS
}

\section{Resumo}

O presente estudo buscou descrever a percepção de universitários sobre sua relação com os professores, bem como identificar a possível influência dessa percepção em sua adaptação acadêmica. Foram entrevistados 29 estudantes dos cursos de Psicologia e Economia de uma universidade do Interior do Rio Grande do Sul. Os relatos dos estudantes foram submetidos à análise fenomenológica, tendo-se identificado cinco aspectos da interação professor-aluno que podem tanto facilitar quanto dificultar a adaptação acadêmica desses jovens: 1- diferenças entre os professores do Ensino Médio e os do Ensino Superior; 2- formação e didática dos professores; 3- receptividade e incentivo; 4- relação acadêmica/ pessoal; e 5- importância atribuída ao professor na formação. Os resultados apontaram a importância de os docentes atuarem com habilidades tanto nos aspectos teórico-didáticos quanto nos aspectos de relação interpessoal. Conclui-se que o papel do professor não se restringe ao ensino teórico e técnico da profissão.

Palavras-chave: Adaptação, interação professor-aluno, universidade.

\section{Perceptions of college students on the professor-student relationship}

\begin{abstract}
In this study we describe college students' perception of their relationship with professors and the influence on their adjustment to college. Twenty nine college students of Psychology and Economy were interviewed. The students' reports were submitted to phenomenological analysis. We identified five aspects of professor-student relationship that may facilitate or make students' college adjustment more difficult: (1) differences between teachers of high school and professors of higher education, (2) professors' background and didactics, (3) receptiveness and incentive, (4) academic and personal relationship, and (5) the importance of professor in higher education. The results show that it is important that professors establish not only theoretical and didactic concepts, but also interpersonal relationships with their students. We conclude that the role of professor is far beyond teaching.
\end{abstract}

Keywords: Adaptation, teacher student interaction, college.

\section{Las percepcioes de estudiantes universitarios sobre la relación profesor-alumno}

\section{Resumen}

Este artículo buscó describir la percepción de universitarios sobre su relación con los profesores, así como identificar su posible influencia en la adaptación académica de los estudiantes. Se entrevistaron 29 estudiantes de Psicología y Economía de una universidad del Interior de Rio Grande do Sul. Se realizó análisis fenomenológico de los datos. Se identificaron cinco aspectos de la interacción profesor-alumno que pueden tanto facilitar como dificultar la transición de esos jóvenes para la Enseñanza Superior: 1- diferenciación de la Enseñanza Media; 2formación y didáctica; 3- receptividad e incentivo; 4- relación académica/personal; y 5-importancia atribuida al profesor en la formación. Se nota la importancia de que los docentes actúen tanto en el nivel teórico como en el nivel personal. Se concluye que el papel del profesor no se restringe a la enseñanza teórica y técnica de la profesión.

Palabras Clave: adaptación; relación profesor-alumno; universidad. 


\section{Introdução}

A adaptação acadêmica no ensino superior refere-se ao ajustamento do indivíduo à vida universitária. Não existe uma definição ou modelo teórico único de adaptação acadêmica, mas algumas dimensões consideradas relevantes no processo de adaptação têm sido destacadas na literatura, como as dimensões acadêmica, social, individual/emocional e institucional. Assim, o grau de adaptação do jovem ao ensino superior pode ser compreendido através das atitudes em relação ao curso, da capacidade de estabelecer novas relações de amizade, à presença ou ausência de estresse e ansiedade frente às demandas acadêmicas e ao vínculo criado com a instituição (Baker \& Siryk, 1984).

O ingresso na universidade é uma fase complexa na vida do estudante, uma vez que demanda a integração do indivíduo a um ambiente que lhe apresenta novas exigências (Teixeira, Dias, Wottrich, \& Oliveira, 2008). Nessa transição, o estudante passa a conviver com novos colegas e novos professores, os quais podem exercer um importante papel na sua adaptação acadêmica (Almeida \& Soares, 2003; Ferraz \& Pereira, 2002).

A influência do professor sobre o aluno não se restringe aos conhecimentos e habilidades ensinados pelo mesmo (Brait, Macedo, Silva, Silva, \& Souza, 2010). Os docentes também são vistos pelos estudantes universitários como modelos profissionais e fontes de apoio e aconselhamento (Bardagi \& Hutz, 2012). Um estudo realizado na Espanha verificou que os aspectos mais mencionados por estudantes universitários sobre o papel ideal do docente correspondem à habilidade de ensinar (habilidade de comunicação, explicação clara sobre as atividades, organização), a sua habilidade de estabelecer uma boa relação professor-aluno (respeito, compreensão, receptividade) e as habilidades sociais dos docentes (facilidade de conversar, justo e não autoritário). Em outras palavras, os discentes esperam que os docentes sejam bons facilitadores do processo de aprendizagem e que os tratem com respeito e consideração (Sánchez, Martinez-Pecino, \& Rodrígues, 2011).

Assim, a relação professor-aluno mostra-se fundamental para a avaliação da qualidade da trajetória universitária (Soares, Almeida, Diniz, \& Guisande, 2006). Esta interação depende, fundamentalmente, do ambiente estabelecido pelo docente, da relação empática com seus alunos, de sua capacidade de ouvir, refletir e discutir o nível de compreensão dos estudantes e da criação das pontes entre o seu conhecimento e o deles (Brait e cols., 2010). Além disso, a disponibilidade dos professores está relacionada a maior adesão ao curso e à profissão, o que pode contribuir para a satisfação com a escolha profissional (Teixeira, Castro, \& Piccolo, 2007).

Não obstante, muitos jovens percebem dificuldades no seu relacionamento com os professores no Ensino Superior. Essas dificuldades podem ser verificadas tanto nos anos iniciais quanto nos anos finais da graduação (Carmo \& Polydoro, 2010). A decepção com o tipo de vínculo estabelecido com os docentes pode ocorrer devido ao distanciamento, à formalidade, às poucas possibilidades de interação social, à percepção de menor interesse pelas questões individuais do aluno ou a outros motivos. A realidade do Ensino Superior pode não corresponder à expectativa dos alunos de manutenção dos vínculos de proximidade e proteção vivenciados na escola (Bardagi \& Hutz, 2012). Os alunos identificam uma diminuição do monitoramento dos professores, que pode ser expressa por uma menor cobrança de desempenho, por exemplo, o que torna necessário um envolvimento mais ativo do estudante com sua formação, aumentando, assim, a sua responsabilidade (Diniz \& Almeida, 2006; Parra, 2008; Soares e cols., 2006).

Verifica-se que os estudos nacionais sobre a qualidade das relações estabelecidas pelos alunos com seus professores na transição para o ensino superior têm se preocupado com a repercussão dessa interação nos processos de ensino-aprendizagem e na motivação dos discentes (Alcará \& Guimarães, 2010; Bariani \& Pavani, 2008; Brait e cols., 2010; Cavaca, Esposti, Santos-Neto, \& Gomes, 2010; Parra, 2008; Quadros e cols., 2010; Veras \& Ferreira, 2010); mas em tais estudos predominam abordagens quantitativas, em geral de caráter correlacional, que não privilegiam o modo como os estudantes vivenciam a relação com os professores e como percebem o impacto dessa relação na sua adaptação acadêmica, especialmente nos aspectos de aprendizagem e de envolvimento com a formação. Em função disso, este estudo buscou descrever a percepção de universitários sobre sua relação com os professores, bem como a influência desta relação na adaptação à universidade.

\section{Método}

\section{Participantes}

Participaram vinte e nove estudantes universitários (vinte e uma mulheres e oito homens) dos cursos de Psicologia e Economia de uma universidade pública do Interior do Rio Grande do Sul. Os alunos estavam cursando o primeiro (dezesseis participantes - sete do curso de Economia e nove do de Psicologia) ou o último ano da graduação (treze participantes - cinco do curso de Economia e oito do de Psicologia). A idade dos acadêmicos variou entre 17 e 23 anos. Alguns estudantes moravam com a família de origem e outros não, pois haviam mudado de cidade para cursar a universidade. Serão utilizados nomes fictícios para se referir aos participantes para preservar o anonimato de suas identidades.

\section{Instrumento e procedimentos}

Foi utilizada uma entrevista com roteiro tópico flexível, especialmente elaborada para este estudo. Tal tipo de entrevista busca circunscrever o tema de interesse, ao mesmo tempo em que oferece liberdade para que o entrevistado construa uma narrativa associando temas que são relevantes em sua experiência pessoal. Assim, busca-se 
o conhecimento do que o informante considera como os aspectos mais importantes em relação a determinada situação de estudo (Richardson, 1999). A entrevista abordou diferentes aspectos relacionados ao processo de adaptação à universidade, tais como os fatores facilitadores e inibidores do mesmo, a relação professor-aluno, a relação com os colegas e com a família de origem, as diferenças entre o Ensino Médio e o Ensino Superior.

Foi realizado contato com as coordenações dos cursos de Economia e Psicologia e com os professores que ministravam aulas para os semestres escolhidos, solicitando autorização para o desenvolvimento do projeto junto a seus alunos. A divulgação sobre o objetivo e os procedimentos do estudo foi coletiva, em sala de aula, convidando os jovens para participar. As entrevistas foram agendadas conforme a disponibilidade dos voluntários e realizadas em local e horário determinado pelo estudante. Destaca-se que a pesquisa foi submetida ao comitê de ética da universidade onde o estudo foi realizado e por ele aprovada.

\section{Análise das informações}

As entrevistas foram transcritas e analisadas a partir do método fenomenológico. A análise foi organizada em três momentos: descrição, redução e interpretação (Gomes, 1998). Na descrição fenomenológica, realizou-se uma síntese geral e não crítica dos temas que descreviam a experiência dos estudantes relacionadas a seus professores, baseada nas informações coletadas na entrevista. Na redução fenomenológica retornou-se à descrição para questioná-la, especificando-se os temas e categorias de análise relevantes a serem aprofundados. Após selecionar os temas e as categorias, voltou-se às entrevistas para localizar frases reveladoras a estes relacionadas. Nesse momento, buscou-se compreender a lógica da categoria em si e como essa se relaciona com as demais categorias encontradas. A exposição da redução foi composta por fragmentos das entrevistas que serviram como evidência da análise realizada. No último passo, a interpretação fenomenológica, fez-se uma reflexão crítica entre o que foi descrito e o que foi reduzido. Nesta etapa final foram confrontados as percepções, a literatura e os sentidos oferecidos pelos entrevistados no intuito de fornecer uma síntese compreensiva da experiência (Gomes, 1998).

\section{Resultados}

As percepções dos universitários foram organizadas em cinco grandes temas referentes às formas como os professores podem influenciar na adaptação à universidade dos estudantes. Esses temas são descritos a seguir.

\section{Diferenças entre os professores do Ensino Médio e do Ensino Superior}

Os estudantes perceberam diferenças entre os professores do Ensino Médio e os e da universidade. De acordo com os entrevistados, há maior cobrança por parte dos professores da escola para participação em aula, desempenho nas tarefas e responsabilidade. Além disso, os alunos consideram que recebiam tudo "mastigado" pelos professores e mantinham uma relação mais próxima com eles, enquanto na universidade eles se depararam com alguns docentes que não fazem cobranças e incentivam os alunos a "se virar".

É diferente, na escola, o professor te exige o livro, e aqui não te exige. Na verdade, é meio tu te puxa, a gente sabe que a gente, tem que fazer o que ele está pedindo porque é o que vai nos fazer bons profissionais. Na escola é meio assim "Ah eu estudo no final para uma prova e vou passar"; aqui não. [...] Eu mesmo tenho que me cobrar mais, porque eu acho que professor de faculdade não exige tanto quanto professor de colégio (Jordana, estudante ingressante de Psicologia).

A gente tem que se virar. Nada mais é mastigado, que o professor dava o resumo do resumo. Aí a gente tem que correr atrás. Eu gosto disso [...] não tem essa coisa mastigadinha (Bianca, estudante ingressante de Economia).

Observa-se que a diferença de atitude dos professores gera nos alunos uma internalização das exigências. Agora eles devem buscar se organizar de modo diferenciado do Ensino Médio para poderem dar conta das exigências desse novo contexto.

\section{Formação e didática dos professores}

Os participantes deste estudo indicaram alguns aspectos referentes à didática dos professores como prejudicial para a sua adaptação à universidade, tais como a cobrança em provas de conteúdos que não foram explicados em aula, a utilização excessiva de seminários como a atividades da disciplina e a falta de estrutura da aula. Alguns alunos também criticaram professores que utilizam o tempo da aula para falar sobre assuntos não referentes à disciplina ou ao curso. Ademais, é possível que os estudantes deixem de se matricular em determinada disciplina por causa do professor que irá ministrá-la.

Essas coisas que não têm nada a ver com o curso mesmo e não têm nada a ver com a matéria sabe, então eu acho que isso não, não me ajudou muito [...] gastam muito tempo da aula falando de outros assuntos que não têm a ver com a aula sabe (Pâmela, estudante ingressante de Psicologia).

Tem professores que deixam muito a desejar, daí tu chega na aula e quem faz a aula é tu. "Bom, o que a gente vai discutir hoje?" Eu, particularmente, acho interessante o professor perguntar as dúvidas que o aluno tem, mas não deixar que o aluno dê aula sempre (Letícia, estudante ingressante de Psicologia).

Eles não passam aquilo que sabem. Tem vários que sabem muito, doutores e tal, mas não passam isso para o aluno e as aulas são muito chatas. Tem umas aulas que começam com a turma cheia, não termina sete, oito, nove no máximo. Claro que não dá pra generalizar, alguns são maravilhosos, te inspiram a querer continuar na área acadê- 
mica e tudo. [...] Várias cadeiras assim... que seriam interessantes pra gente, a gente não faz porque é um determinado professor que vai dar a aula sabe. Então a gente já conhece que a didática é horrível e às vezes coloca coisas na prova que eles mesmo não sabem responder, então a gente não faz aquela disciplina por causa disso (Fernanda, estudante concluinte de Economia).

Os estudantes também mencionaram elementos da formação e didática dos professores que foram considerados facilitadores para sua adaptação acadêmica. Os alunos julgam fundamentais uma boa formação, a transmissão de conhecimentos e experiências, a motivação de discussões e gostar daquilo que faz como fundamentais para ser um bom professor.

Isso é uma coisa que influencia. [...] Um professor bom. Saber daquilo que ele está falando, [...] motivar a discussão e fazer com que ela seja produtiva. Isso conta muito pra o professor ser bom, porque ele vai conseguir fazer aparecer vários pontos de vista, vai dar pra enxergar muito melhor tudo o que ele está explicando [...]. O fato do professor ser bom e gostar daquilo que faz é uma coisa que meio que segura bastante na universidade (Hélio, estudante concluinte de Psicologia).

A maneira com que dá aula, isso transparece assim, [...] a gente acaba [...] se espelhando, eu acho. E isso soma para a minha capacidade crítica e reflexiva, além dos textos dados em aula, da maneira de ministrar as aulas, eu acho que tem isso assim, a ética [...], o comportamento (Nicole, estudante concluinte de Psicologia).

Eles têm que dar exemplo para nós seguirmos, para não poder desistir, dando provas melhores, explicando, dando mais informação (Leonardo, estudante ingressante de Economia).

\section{Receptividade e incentivo}

Foi possível perceber quanto a receptividade e o incentivo dos professores são importantes para a adaptação acadêmica dos estudantes. Muitos alunos consideraram o descaso aparente, a inacessibilidade e a postura superior de alguns docentes como fatores que podem causar dificuldades na sua transição para o Ensino Superior. Os universitários explicaram que muitos professores agem de forma autoritária e rígida, amedrontando-os. Devido a esse distanciamento, muitos jovens não se sentem à vontade para se aproximar e tirar dúvidas junto aos professores:

Eu acho que eles dão pouco incentivo. Isso ajuda no indice de evasão. Eles poderiam trabalhar mais essas questões. Parece que eles não se importam muito "ah, se tu quer, tu fica aí, é isso que eu tenho a oferecer" (Diana, estudante concluinte de Economia).

O que dá para sentir que não é legal quando um professor vem e quer impor autoridade na sala [...], que ele quer mostrar que os alunos estão mais para baixo e ele está mais para cima e se impõe (Camila, estudante ingressante de Psicologia).
No primeiro semestre tem professores que ficavam botando medo na gente [...] e fazia um terrorismo dentro da aula, quando na verdade eu acho que isso é errado, tu tem que incentivar o pessoal a ir bem [...]. Eu acho que nesse sentido eles podem nos ajudar tentando ser mais paternalista de "vocês conseguem, vocês podem" (Leandro, estudante ingressante de Economia).

Tem uns que tu fica com a impressão de que eles te veem como um concorrente, parece que eles querem te tirar do caminho, querem mesmo que você desista, largue o curso, sei lá [...] (Raquel, estudante ingressante de Economia).

Em contrapartida, os estudantes que participaram deste estudo identificaram características dos professores que parecem facilitar sua adaptação acadêmica. Os exemplos mais citados foram boa educação, simpatia, oferecer abertura e incentivo aos alunos.

Tem professores que a gente sente que tem liberdade para questionar, para perguntar, se sente à vontade [...] e eu acho que isso é o que propicia que a gente busque, discuta, consiga também produzir conhecimento (Laís, estudante concluinte de Psicologia).

Tem alguns que se tu tiver "vamo lá, eu te ajudo, você consegue", tem professor que é bem camarada assim (Raquel, estudante ingressante de Economia).

\section{Relação acadêmica/pessoal}

Verificou-se que o distanciamento dos professores pode impossibilitar uma relação mais próxima e pessoal entre aluno e docente. Os universitários relataram que alguns professores demarcaram uma diferenciação entre professor e aluno, estabelecendo uma relação estritamente acadêmica entre ambos. Além disso, perceberam que não havia preocupação de alguns professores em relação à adaptação acadêmica dos estudantes.

Com os professores isso tinha uma distância bem clara. Cada vez eu me sentia mais aluna e os professores mais professores [...]. Essa relação que eu considero que é mais ampla, pra mim, faz falta (Nicole, estudante concluinte de Psicologia).

No geral eles são bem fechados e se não é aquilo ali que tu quer, eu acho que acaba te desestimulando (Diana, estudante concluinte de Economia).

No início os professores se restringiam a entrar na sala, dar bom-dia, cumprir o seu conteúdo e ir embora. Isso possibilitava todos os mitos que a gente criava em torno deles, inclusive porque não tinha informações acerca deles (César, estudante concluinte de Psicologia).

Já os laços de amizade e respeito entre professores e alunos podem facilitar a adaptação à universidade. Quando há uma relação mais próxima entre ambos, torna-se possível maior interação, troca de experiências e conhecimentos. Ademais, verificou-se que os alunos gostariam que os professores se preocupassem com o seu ajustamento ao ensino superior e formação. 
Acho que às vezes teria que dar um pouco de pessoal assim [...] tentar se identificar com o aluno, perguntar como é que estão, alguma coisa assim... sabe, dar bom-dia (Lúcio, estudante ingressante de Psicologia).

Eu gostaria de conversar mais com os professores. [...] Eu acho que o professor é uma pessoa que pode estar sempre te ajudando, então eu acho que devia ser mais pessoal, eu queria, acho legal ter uma amizade com professor, não ser aquela coisa só o professor ensina, o aluno aprende (Pâmela, estudante ingressante de Psicologia).

Quando ele se coloca como amigo da turma e conversa mais assim [...] quando ele se aproxima mais, conversa, participa das coisas, das festas. Eu acho que assim que o professor consegue conquistar mais o aluno (Aline, estudante ingressante de Psicologia).

O que facilita é essa abertura, ser mais amigo do aluno. Não é que tu precise sair, fazer festa, ir para um barzinho com o aluno, não é isso, mas encontrar no corredor e cumprimentar. Tem professores que passam de cabeça baixa. [...] Acho que isso não é uma obrigação, mas acho que não custa, acho que seria bom, facilita (Letícia, estudante ingressante de Psicologia).

\section{Importância atribuída ao professor na formação}

Os estudantes percebem que os docentes são importantes para seu aprendizado e formação, apesar das diversas dificuldades em relacionar-se com eles. De acordo com os participantes deste estudo, o professor não deve apenas transmitir conhecimento, mas também ser amigo e facilitador da sua adaptação à universidade.

O professor é muito importante na adaptação do aluno. Eu acho que atuar como facilitador, além de estar em uma posição de ensino, de passar conhecimento, eu acho que até por já ter passado pela experiência da universidade, facilitar um pouco mais para o aluno entender o que está se passando (Franciele, estudante concluinte de Psicologia).

O papel do educador é fazer a ponte entre esse conhecimento elaborado e aquilo que diz da realidade do aluno. [...] É construir conhecimento, estar propiciando que se construa o conhecimento, a aprendizagem [...] acho que os nossos professores têm que batalhar por isso em todos os sentidos... assim... tentar se preocupar com a nossa formação e da gente estar podendo crescer, e isso implica também não só em estar transferindo um conhecimento pra gente (Laís, estudante concluinte de Psicologia).

Os alunos também acreditam que os docentes podem influenciar no interesse ou não do estudante por uma disciplina, dependendo da forma como ministram as aulas. Além disso, podem auxiliá-los no direcionamento de sua formação e carreira. Assim, os professores são considerados pelos estudantes como modelo e exemplo a ser seguido.

Ah, eu acho muito importante, por exemplo, eu tenho uma cadeira que essa matéria eu acho importante e a professora não torna ela interessante, então tu acaba se desinteressando do que tu gostava por causa da professora.
Já matérias que não são tão legais pra ti, tu acaba gostando por causa do professor (Fabiano, estudante ingressante de Economia).

A importância que os professores têm? Eu acho que, fora ensinar, dar a matéria, explicar, eles têm a importância muitas vezes de tu definir qual o ramo que tu quer seguir da faculdade. Alguns inspiram os alunos a seguir tal área, acho que essa é a principal (Daniela, estudante concluinte de Economia).

Tanto nos ensinar até como referencial assim. Daí tu olha para o professor já bem-sucedido como modelo que tu fica assim bah, olha só, conseguiu tudo isso, quero também conseguir desempenhar tudo isso". Vai atrás e sabe que é possivel fazer isso (Denise, estudante ingressante de Psicologia).

A postura que ele assume diante da vida, diante do trabalho, diante das relações que ele estabelece, [...] essa postura é o que a gente aprende. Tu ter modelos disso, eu acho que essa é a importância na Psicologia, e eu acredito que em outros cursos a forma como o professor assume a postura profissional também é interessante, porque isso em um livro é difícil de sentir. Acho que esse seria o papel do professor (Andressa, estudante concluinte de Psicologia).

\section{Discussão}

Os relatos dos entrevistados evidenciam a grande importância atribuída pelos estudantes universitários aos professores e ao relacionamento que com eles estabelecem. A relação entre docente e aluno pode tanto facilitar quanto dificultar a adaptação do discente ao ensino superior, através dos comportamentos, postura e didática dos professores.

No processo de transição para a universidade muitos alunos carregam altas expectativas em relação ao curso e às relações que serão estabelecidas no Ensino Superior (Polydoro, 2001). As dificuldades no relacionamento com alguns professores, além da falta de didática - que envolve tanto o seu desempenho em sala de aula como a sua competência e sua capacidade de ensinar -, podem desfazer essas expectativas (Pachane, 2003; Teixeira e cols., 2008). Assim, é possível que os estudantes vivenciem sentimentos de decepção, de forma que sua impressão sobre a universidade deixe de ser tão positiva (Polydoro, 2001).

De fato, as relações estabelecidas na universidade, especialmente entre professores e alunos, assumem papel primordial na compreensão da qualidade da experiência universitária (Soares e cols., 2006). A percepção dos estudantes sobre a disponibilidade dos docentes parece promover uma maior adesão aos valores associados ao curso e à profissão, contribuindo para a satisfação com a escolha profissional. Ademais, os próprios laços estabelecidos com os professores estão associados a sentimentos de satisfação com a universidade, uma vez que possibilitam ao discente um maior envolvimento com a instituição (Teixeira e cols., 2007). Tais constatações revelam que a frequência de contato com docentes e a similaridade de valores em assuntos 
não acadêmicos são necessárias para a persistência do estudante na trajetória universitária (Teixeira e cols., 2008).

Neste sentido, é fundamental que o professor apresente condições favoráveis de ensino e relacionamento com os alunos e compartilhe com eles seus conhecimentos profissionais e sociais (Parra, 2008). A afetividade pode ser expressa tanto nas interações sociais como na prática pedagógica, através do planejamento da disciplina, da consideração sobre os limites e possibilidades dos alunos, da escolha dos procedimentos de ensino, do acompanhamento ao aluno, do feedback no decorrer do processo de ensino e aprendizagem e do compartilhamento das responsabilidades que as situações pedagógicas exigem (Veras \& Ferreira, 2010).

O conhecimento transmitido pelo docente é compreendido pelos estudantes como um aprendizado para toda a vida, não apenas como conteúdo acadêmico. Assim, os alunos esperam um tratamento que inclua aspectos que vão além do conteúdo, como a postura, a ética, o respeito e a sensibilidade (Quadros e cols., 2010). Uma interação baseada nesses comportamentos pode servir como modelo para as futuras relações profissionais estabelecidas pelos discentes (Cavaca e cols., 2010). Sabe-se que, de fato, o comportamento do professor como expressão de sentimentos positivos ou de desagrado, a oferta de feedback positivo, agradecimentos e pedidos de mudança de comportamento, podem promover melhorias nas habilidades sociais dos alunos em fase escolar (Rocha \& Carrara, 2011). A partir disso, questiona-se se o comportamento dos professores universitários também pode aumentar as interações em sala de aula e modelar o comportamento dos alunos.

Os docentes em geral parecem não reconhecer a sua verdadeira função no processo ensino-aprendizagem. Muitos professores ainda não compreendem que o seu papel de educador ultrapassa a transmissão técnica dos conteúdos (Bariani \& Pavani, 2008). Por outro lado, os discentes possuem clareza quanto às características de um bom professor: "saber se relacionar", "considerar os questionamentos dos alunos", ser atualizado, estar disponível em horários além dos de sala de aula, contextualizar o conhecimento, exercer autoridade sem ser autoritário, ser pontual e organizado (Quadros e cols., 2010). Isso pode ser ilustrado pela diferença nas perspectivas de estudantes e docentes no que se refere aos procedimentos de aula. Enquanto os professores acreditam que a técnica pedagógica faz com que os alunos se interessem pelas aulas, os discentes atentam também para a capacidade do docente de contextualizar a matéria com a vida dos estudantes com o intuito de motivá-los a aprender. De fato, os procedimentos de aula são apontados como o principal elemento que desperta interesse e incentiva a participação dos alunos na aula (Bariani \& Pavani, 2008). Assim, cabe ao professor articular as atividades propostas em aula com a atuação profissional futura (Alcará \& Guimarães, 2010).

Percebe-se que pode haver um distanciamento entre professores e alunos devido à falta de abertura de alguns docentes e à dificuldade de um relacionamento mais próximo com os estudantes. Um estudo conduzido por Cavaca e cols. identificou alguns fatores que podem influenciar negativamente o processo de ensino e aprendizagem, como a falta de acessibilidade e de interação pedagógica e social entre os atores, a arrogância e a intimidação por parte de professores e a falta de compreensão de limites por parte dos alunos (Cavaca e cols., 2010). A percepção de maior distanciamento, formalidade excessiva, menor envolvimento dos professores com as questões individuais dos discentes, falta de interesse em construir relações pessoais e até certa competitividade dos docentes correspondem a queixas frequentes de alunos evadidos. Percepções de que os professores não transmitem paixão ou conhecimento suficiente para a posição que ocupam e percepções sobre falta de didática também podem ser comuns (Bargadi \& Hutz, 2012). De fato, muitos docentes estão capacitados teoricamente para ensinar, mas não conseguem estabelecer uma relação amistosa com o estudante mostrar interesse e preocupação com eles; porém para uma efetiva construção de conhecimento ele precisa ter didática e manter com alunos relações interpessoais satisfatórias (Parra, 2008). O interesse de professores no aprendizado dos discentes parece funcionar como estímulo para a adesão ao curso, enquanto o desinteresse estimula o desengajamento dos jovens (Teixeira e cols., 2008). Mais que isso, as dificuldades de relacionamento com docentes podem não só aumentar a insatisfação com a experiência acadêmica, mas inclusive favorecer o abandono de curso (Bardagi \& Hutz, 2012).

Por outro lado, existem aspectos do próprio aluno que podem dificultar sua interação com o professor, como dificuldades de cunho psicológico que envolvem tanto alterações de humor quanto dificuldades de concentração e ansiedade Assim, é possível que estudantes que demonstrem desinteresse pelo aprendizado, por exemplo, não desfrutem da mesma disponibilidade dos docentes para atendê-los como atendem discentes mais comprometidos com seu processo de aprendizagem (Teixeira e cols., 2007). Além disso, há determinadas atitudes em sala de aula que podem indispor os professores para estabelecer boas relações com os alunos, como perguntas para chamar a atenção, para testar o conhecimento do professor sobre um assunto que o professor acabou de explicar (como se não o tivessem escutado), ou ainda perguntas extremamente óbvias, percebidas pelo professor como se fossem apenas para "irritá-lo" (Quadros e cols., 2010).

É possível que uma das causas das dificuldades enfrentadas quando se trata da relação professor-aluno corresponda ao desconhecimento das expectativas de ambos e à diferença entre elas. O não entendimento dos objetivos dos alunos, que esperam dedicação e envolvimento dos docentes, e dos professores, que esperam um tratamento impessoal e profissional dos discentes, pode gerar conflitos. Se esse for o caso, o docente pode aparentar superioridade em sala de aula e as ações dos estudantes podem ser consideradas uma afronta ao professor (Quadros e cols., 2010). A partir disso, pode-se pensar que as crenças dos docentes universitários também influenciam seu comportamento e, 
consequentemente, também o processo ensino-aprendizagem de seus alunos.

Em vista da importância atribuída pelos estudantes ao professor universitário e da relevância de seu papel no âmbito da carreira, como modelo de identificação de papel de trabalho (que também pode ser modelo negativo de carreira), torna-se importante construir um modelo de interação que contemple os aspectos técnicos e afetivos da troca entre discentes e docentes no Ensino Superior (Bardagi \& Hutz, 2012). Em uma pesquisa conduzida por Quadros e cols. (2010) constatou-se que não há um "contrato" de trabalho no qual constem as expectativas quer do professor quer dos estudantes, a não ser conteúdo, objetivos e metas. Em outras palavras, verifica-se que muitas vezes os alunos não compreendem o que o professor espera deles, e este, por sua vez, também não consegue contemplar as expectativas daqueles, provavelmente por desconhecimento. A partir disso, os autores sugerem que o professor promova a discussão deste contrato, de forma a se tornarem mais explícitos os objetivos e as expectativas de ambas as partes (Quadros e cols., 2010). Assim, é possível que os professores estabeleçam uma relação baseada no diálogo e na amizade com os alunos sem se esquecer da autoridade que exercem nessas interações (Veras \& Ferreira, 2010).

\section{Conclusões}

Este estudo buscou descrever a percepção de universitários sobre sua relação com os professores e a influência desta na sua adaptação à universidade. Os relatos dos estudantes permitiram identificar cinco aspectos dessa interação que podem tanto facilitar quanto dificultar a transição desses jovens para ao ensino superior, a saber: diferenças entre os professores do ensino médio e do ensino universitário, formação e didática dos professores, receptividade e incentivo, relação acadêmica/pessoal e importância do professor na formação. A partir disso, nota-se a importância de os docentes atuarem tanto no nível teórico-didático, através da transmissão do conhecimento e de experiências e da motivação de discussões, quanto no nível interpessoal, mostrando-se abertos ao diálogo e preocupados com a adaptação acadêmica e formação dos discentes, auxiliando-os na orientação quanto à carreira. Ademais, parece que a proximidade afetiva e conversas sobre assuntos não relacionados ao curso ou à profissão também podem favorecer a satisfação com a experiência universitária, uma vez que uma interação professor-aluno de qualidade está associada com adaptação acadêmica. Constata-se, assim, que o papel do professor não se restringe ao ensino teórico e técnico da profissão.

Embora o objetivo desta pesquisa tenha sido contemplado, esta possui algumas limitações que devem ser mencionadas. Foram entrevistados estudantes universitários de apenas dois cursos (Psicologia e Economia) de uma universidade pública do interior do Rio Grande do Sul. É possível que discentes de outros cursos possuam expectativas e per- cepções diferentes sobre sua relação com os professores. Além disso, o relacionamento estabelecido com docentes de universidades particulares pode ter características não encontradas em instituições públicas. Ressalta-se, ainda, que os presentes resultados podem também ter sido enviesados por questões de gênero dos estudantes (predominantemente do sexo feminino). A partir disso, sugere-se que mais pesquisas sejam realizadas abrangendo acadêmicos de cursos de outras áreas, como saúde e exatas, no intuito de verificar se os elementos valorizados nas relações com os professores e a própria interação com estes são diferentes. Estudos com estudantes universitários satisfeitos com a relação estabelecida com os docentes também podem ser úteis para verificar se os diálogos sobre assuntos não relacionados ao curso ou profissão são realmente importantes para a adaptação acadêmica e para identificar em que contextos se dão as interações extraclasse.

Questiona-se, ainda, se os docentes percebem a importância creditada a eles pelos estudantes, se buscam dar conta dessas expectativas, de que forma isso ocorre e as possíveis dificuldades encontradas. Dessa forma, sugere-se que mais estudos sejam realizados abordando a percepção dos próprios professores sobre sua atuação. Estes dados podem favorecer a criação de programas de orientação e instrumentalização desses profissionais para melhor desempenho da sua função.

\section{Referências}

Alcará, A. R., \& Guimarães, S. E. R. (2010). Orientações motivacionais de alunos do curso de biblioteconomia. Psicologia escolar e educacional, 14(2), 211-220.

Almeida, L. S., \& Soares, A. P. (2003). Os estudantes universitários: sucesso escolar e desenvolvimento psicossocial. Em E. Mercuri \& S. A. J. Polydoro (Eds.), Estudante universitário: características e experiências de formação (pp. 15-40). Taubaté, SP: Cabral.

Baker, R. W., \& Siryk, B. (1984). Measuring adjustment to college. Journal of Counseling Psychology, 31(2), 179-89.

Bardagi, M. P., \& Hutz, C. S. (2012). Rotina acadêmica e relação com colegas e professores: impacto na evasão universitária. Psico, 43(2), 174-184.

Bariani, I. C. D., \& Pavani, R. (2008). Sala da aula na universidade: espaço de relações interpessoais e participação acadêmica. Estudos de Psicologia, 25(1), 67-75.

Brait, L. F. R., Macedo, K. M. F., Silva, F. B., Silva, M. R., \& Souza, A. L. R. (2010). A relação professor/aluno no processo de ensino e aprendizagem. Itinerarius Reflectionis, 8(1), 1-15.

Carmo, M. C., \& Polydoro, S. A. J. (2010). Integração ao Ensino Superior em um curso de Pedagogia. Psicologia escolar e educacional, 14(2), 211-220. 
Cavaca, A. G., Esposti, C. D. D., Santos-Neto, E. T., \& Gomes, M. J. (2010). A relação professor-aluno no ensino da Odontologia na Universidade Federal do Espírito Santo. Trabalho, educação e saúde, 8(2), 305-318.

Diniz, A. M., \& Almeida, L. S. (2006). Adaptação à Universidade em estudantes do primeiro ano: Estudo diacrónico da interacção entre o relacionamento com pares, o bem-estar pessoal e o equilíbrio emocional. Análise Psicológica, 1(24), 29-38.

Ferraz, M. F., \& Pereira, A. S. (2002). A dinâmica da personalidade e o homesickness (saudades de casa) dos jovens estudantes universitários. Psicologia, Saúde \& Doenças, 3(2), 149-164.

Gomes, W. B. (1998). A entrevista fenomenológica e o estudo da experiência consciente. Em W. B. Gomes, Fenomenologia e pesquisa em psicologia (pp. 19-44). Porto Alegre: Editora da Universidade/UFRGS.

Pachane, G. G. (2003). A experiência universitária e sua contribuição ao desenvolvimento pessoal do aluno. Em E. Mercuri \& S. A. J. Polydoro (Eds.), Estudante universitário: características e experiências de formação (pp. 155-186). Taubaté, SP: Cabral.

Parra, C. R. (2008). Contribuições da Psicologia para a compreensão da relação professor $X$ aluno no Ensino Superior. Dissertação de Mestrado, Universidade do Oeste Paulista, Presidente Prudente, SP.

Polydoro, S. A. J. (2001). O trancamento de matrícula na trajetória acadêmica do universitário: condições de saída e de retorno à instituição. Tese de Doutorado, Universidade Estadual de Campinas, Campinas,SP.
Quadros, A. L., Lopes, C. M., Silva, F. A. B., Correa, J. M. M., Pio, J. M., Torres, N. O., Pinto, P. L., \& Nogueira, R. K. (2010). A percepção de professores e estudantes sobre a sala de aula de ensino superior: expectativas e construção de relações no curso de Química da UFMG. Ciência \& educação, 16(1), 103-114.

Richardson, R. J. (1999). Pesquisa social: métodos e técnica. São Paulo, Atlas.

Rocha, J. F., \& Carrara, K. (2011). Formação ética para a cidadania: reorganizando contingências na interação professor-aluno. Revista escolar e educacional, 15(2), 221-230.

Sánchez, M. M., Martinez-Pecino, R. M., \& Rodrígues, Y. T. (2011). Student perspectives on the university professor role. Social behavior and personality, 39(4), 491-496.

Soares, A. P., Almeida, L. S., Diniz A. M., \& Guisande M. A. (2006). Modelo multidimensional de ajustamento de jovens ao contexto universitário (MMAU): Estudo com estudantes de ciências e tecnologias versus ciências sociais e humanas. Análise Psicológica, 1(24), 15-27.

Teixeira, M. A. P., Castro, G. D., \& Piccolo, L. R. (2007). Adaptação à universidade em estudantes universitários: um estudo correlacional. Interação em Psicologia, 11(2), 211-220.

Teixeira, M. A. P., Dias, A. C. G., Wottrich, S. H., \& Oliveira, A. M. (2008). Adaptação à universidade em jovens calouros. Revista Semestral da Associação Brasileira de Psicologia Escolar e Educacional, 12(1), 185-202.

Veras, R. S., \& Ferreira, S. P. A. (2010). A afetividade na relação professor-aluno e suas implicações na aprendizagem, em contexto universitário. Educar em revista, 38, 219-235.

Recebido em: 04/12/2012

Reformulado em: 23/08/2013

Aprovado em: 16/12/2013

\section{Sobre os autores}

Clarissa Tochetto de Oliveira (clarissa.tochetto@gmail.com)

Mestranda e Bolsista CAPES/DS do Programa de Pós-Graduação em Psicologia (PPGP) da Universidade Federal de Santa Maria (UFSM), Santa Maria, RS, Brasil.

Jamille Mateus Wiles (jamillemw@hotmail.com)

Foi bolsista FIPE-SR-UFSM junto ao PPGP da UFSM. Pós-graduanda em Atendimento Clínico na Universidade Federal do Rio Grande do Sul. Porto Alegre, RS, Brasil.

Pascale Chechi Fiorin (paca_psi@yahoo.com.br)

Foi Bolsista CAPES/DS. Mestre em Psicologia pelo PPGP/UFSM. Santa Maria,

Ana Cristina Garcia Dias (anacristinagarciadias@gmail.com)

Doutora em Psicologia Escolar e do Desenvolvimento (USP), professora do PPGP da UFSM. Santa Maria, RS, Brasil.

Agradecimento ao financiamento do Fundo de Incentivo à Pesquisa (FIPE Sênior) da Universidade Federal de Santa Maria. 